\title{
EL EMPRESARIO \\ COMO FACTOR DE PRODUCCION
}

\author{
MANUEL SANTOS REDONDO \\ Universidad Complutense de Madrid
}

El objeto de mi investigación es analizar la figura del EMPRESArio en el proceso de producción. La hipótesis de trabajo es que el empresario es un FACTOR DE PRODUCCION específico, que no puede subsumirse como capital ni como trabajo. Pretendo desarrollar en qué consiste esa función específica del empresario, y cómo se retribuye en el sistema económico en el que vivimos, de economía de mercado. (Aunque hagamos también referencia a cuál sería esa función - esencialmente la misma-, quién la desem. peña y cómo se retribuye - aquí sí hay diferencias- en un sistema de economía planificada con dirección estatal.)

El problema que pretendo resolver es una laguna dentro de la teoría económica actual. A pesar de las precisiones y advertencias previas que suelen hacerse contra el análisis estático, a la hora de desarrollar el pretendido análisis dinámico no se pasa de una simple estática comparativa. Es este enfoque el que impide que el empresario aparezca con claridad en el análisis económico, pues su función está siempre relacionada con el desequilibrio y con el movimiento de la economía hacia el estado de equilibrio. Es decir, la función del empresario sólo existe, y por tanto sólo es visible, en el tránsito entre dos estados que son los que estudiamos en un análisis de estática comparativa. Hemos de recurrir, entonces, si queremos que el empresario aparezca en el modelo, a artificios teóricos, como hizo Walras: mantener al empresario en su modelo de equilibrio general, otorgándole una función económica, pero no una retribución por dicha función («empresario que no obtiene beneficios ni pérdidas»). Pues no puede haber beneficio empresarial puro más que en condiciones que no cumplan los requisitos del equilibrio estático.

La afirmación de que el empresario es realmente un factor de producción no es contraria, en absoluto, a la idea de que la economía tiende al equilibrio. Lo único que se afirma es que la ganancia específica del empresario está en ese tránsito hacia el equilibrio; y que si estudiamos la realidad a través de un modelo teórico ideal de equilibrio general, al que aceptamos 
que tiende (por sí sola o con intervención estatal), es necesario completar el análisis con el estudio, aparte de la figura teórica del empresario. Esta figura del empresario, por la forma de acercarnos teóricamente a la realidad, ha quedado fuera de nuestro modelo general, sin que ese modelo teórico general sea en modo alguno incompatible con la existencia del empresario en la economía real.

En esta dirección han trabajado los economistas que, hasta el momento actual, se han ocupado del empresario: Knight, Schumpeter... La función del empresario se relaciona siempre con el cambio económico rápido; aparte de perturbaciones extraeconómicas, ésta es la fuente principal de oportunidades para el empresario. Es en una economía en rápido e imprevisible progreso donde tiene sentido hablar de la función empresarial. De aquí la importancia y la oportunidad del estudio del empresario en los momentos actuales, en que tanto los políticos como los economistas «descubren» al empresario como motor de la economía, creador de empleo y fuente de progreso económico. Así, se habla ahora extensamente de la necesidad de empresarios; se intenta aparecer como «empresario", aprovechando la indudable buena imagen que el término tiene, frente a las connotaciones negativas de las palabras «patrono» o «capitalista»; se reclama para el Estado, los Ayuntamientos..., el calificativo de «empresario»; se crean incluso organismos públicos - y tam. bién empresas privadas - destinados a promover y facilitar la aparición de nuevos empresarios; sin que todo este movimiento de propaganda, y también de fondos públicos y privados se apoye en ningún desarrollo teórico.

Con la confusión correspondiente, pues no se diferencia el llamado empresario del capitalista, o del trabajador por cuenta propia, o del gestor («ejecutivo»), o del «creador de empresas» que siguen exactamente la pauta de las ya existentes, sin contribuir a la creación de ningún nuevo producto ni organizar la producción de ninguna manera nueva (esto es, sin descubrir - ni satisfacer-- ninguna «demanda latente» en la sociedad, ni contribuir a crear una nueva).

Aceptando como hipótesis de trabajo que no puede haber desarrollo económico sin función empresarial; que el empresario cumple siempre una función importante pero más aún en época de rápidos e imprevisibles cambios y de oportunidades escondidas y fugaces que no rodo el mundo descubre, o acepta el riesgo de buscar; aceptando lo acertado de esta idea, pretendemos desarrollarla teóricamente, definiendo la función empresarial; diferenciándola de otras funciones económicas (que sí recoge la herramienta teórica que manejamos normalmente), y presentando una teoría del empresario susceptible de contrastación econométrica.

En esta última parte del trabajo intentaré convertir lo que es una teoría general del empresario en pequeños modelos aptos para la contrastación eco- 
nométrica, en la misma dirección en que Stigler (The Organization of Indus. try, 1968) lo intenta para la economía norteamericana. Así, puesto que la tesis de la teoría del empresario es que el progreso económico rápido e imprevisible es la fuente principal de oportunidades para el empresario, y por tanto también de beneficios empresariales puros, hemos de concluir que la tasa de beneficios depende de factores aleatorios; no hay relación entre la aparición de beneficio empresarial puro y las variables conocidas, pues se debe precisamente a las variaciones imprevistas de la economía. En este sentido, decimos que, en la Bolsa, la existencia de beneficios, en el pasado, de una Compañía no significa nada respecto a si los va a tener o no en el futuro; o, tal como hace Stigler, midiendo el grado de concentración en los diversos sectores de la economía y relacionándolo con la tasa de beneficio, podemos descartar, si no encontramos esa relación, que el beneficio empresarial sea simplemente una renta de monopolio. Aunque este estudio es difícil, tanto por su carácter novedoso como por lo complejo de la materia, se puede conseguir al menos «desbrozar» el campo de estudio y avanzar en la dirección de presentar la teoría del empresario como susceptible de contrastación empírica con los conocimientos y datos de que disponemos en la actualidad. 